\title{
Presence of the minor EGFR T790M mutation is associated with drug-sensitive $E G F R$ mutations in lung adenocarcinoma patients
}

\author{
SHINSUKE HASHIDA ${ }^{1}$, JUNICHI SOH ${ }^{1}$, SHINICHI TOYOOKA ${ }^{1,2}$, TOMOAKI TANAKA ${ }^{3}$, \\ MASASHI FURUKAWA ${ }^{1}$, KAZUHIKO SHIEN ${ }^{1,2}$, HIROMASA YAMAMOTO ${ }^{1}$, HIROAKI ASANO ${ }^{1}$, \\ KAZUNORI TSUKUDA $^{1}$, KOICHI HAGIWARA ${ }^{3}$ and SHINICHIRO MIYOSHI ${ }^{1}$
}

\begin{abstract}
Departments of ${ }^{1}$ Thoracic Surgery and ${ }^{2}$ Clinical Genomic Medicine, Okayama University Graduate School of Medicine, Dentistry and Pharmaceutical Sciences, Okayama, Okayama 700-8558; ${ }^{3}$ Department of Respiratory Medicine, Saitama Medical University, Moroyama, Saitama 350-0495, Japan
\end{abstract}

Received March 4, 2014; Accepted April 22, 2014

DOI: $10.3892 /$ or.2014.3197

\begin{abstract}
The T790M mutation in the epidermal growth factor receptor $(E G F R)$ gene is known to be associated with the acquired resistance of lung adenocarcinoma patients to EGFRtyrosine kinase inhibitors (EGFR-TKIs). The minor T790M mutant allele is occasionally detected in EGFR-TKI-naive tumor samples, yet findings concerning the clinical impact of the minor T790M mutation vary among previous studies. In the present study, we assessed the clinical impact of the minor T790M mutation using a novel, highly sensitive assay combining high-resolution melting (HRM), mutant-enriched PCR and co-amplification at a lower denaturation temperature (COLD)-PCR. We determined the T790M mutational status in 146 surgically resected lung adenocarcinomas without a history of EGFR-TKI treatment using mutant-enriched COLD-HRM (MEC-HRM) and standard HRM assays. The sensitivities of the MEC-HRM and standard HRM assays for the detection of T790M-mutant alleles among wild-type alleles were 0.01 and $10 \%$, respectively. Although the T790M mutation was not detected using a standard HRM assay, we identified 19 (13\%) T790M mutations using the MEC-HRM assay and defined these 19 mutations as minor T790M mutations. The proportion of $\mathrm{T} 790 \mathrm{M}$ alleles was $<0.1 \%$ in $17(84 \%)$ of the 19 samples. Multivariate analyses revealed that a minor T790M mutation was significantly associated with the presence of
\end{abstract}

Correspondence to: Professor Shinichi Toyooka, Department of Thoracic Surgery, Okayama University Graduate School of Medicine, Dentistry and Pharmaceutical Sciences, 2-5-1 Shikata-cho, Kita-ku, Okayama 700-8558, Japan

E-mail: toyooka@md.okayama-u.ac.jp

Abbreviations: HRM, high resolution melting; EGFR, epidermal growth factor receptor; TKI, tyrosine kinase inhibitor; PCR, polymerase chain reaction; RFLP, restriction fragment length polymorphism; COLD-PCR, CO-amplification at lower denaturation temperature PCR; MEC-HRM, mutant-enriched COLD-HRM

Key words: T790M mutation, high resolution melting analysis, mutant-enriched PCR, COLD-PCR, drug resistance
EGFR exon 19 deletions or the L858R mutation (both of which are drug-sensitive $E G F R$ mutations) $(\mathrm{P}=0.04)$. In conclusion, the minor EGFR T790M mutations were present in $13 \%$ of EGFR-TKI-naive surgically resected lung adenocarcinomas and were associated with drug-sensitive EGFR mutations.

\section{Introduction}

Activating mutations of the epidermal growth factor receptor $(E G F R)$ gene are characteristic genetic alterations in nonsmall lung cancer (NSCLC) patients, particularly in those with lung adenocarcinomas (1-3). EGFR exon 19 deletions or the exon 21 L858R mutation account for more than $90 \%$ of all EGFR mutations $(4,5)$. Of particular importance, these mutations are known as predictors of a favorable clinical outcome in response to treatment with EGFR-tyrosine kinase inhibitors (EGFR-TKIs) $(1,2)$. Although $~ 80 \%$ of NSCLC patients with drug-sensitive EGFR mutations such as EGFR exon 19 deletions or the exon 21 L858R mutation initially show satisfactory responsiveness to EGFR-TKI treatment $(1,2)$, acquired resistance to EGFR-TKIs occurs in most cases (6). Half of all resistance to EGFR-TKIs is caused by an acquired T790M mutation in exon 20 of the EGFR gene (7-9). The T790M mutation has been reported to cause EGFR-TKI resistance by sterically hindering the binding site of gefitinib and erlotinib, two first-generation EGFR-TKIs (7), thereby causing a relative decrease in binding with EGFR-TKIs (10).

The T790M mutation has been detected in some patients who have not been treated with EGFR-TKIs (11-16). Since the incidence of a $\mathrm{T} 790 \mathrm{M}$ mutation has been reported to range from 0.02 to $0.05 \%$ in all surgically resected NSCLC patients based on studies using direct sequencing $(2,17)$, it is difficult to clarify the association due to the T790M mutation and clinicopathological factors because of the limitation in the number of cases. Using highly sensitive assays, the clinical impact of the minor T790M mutation in NSCLC patients with EGFR-TKI treatment has been previously investigated $(11,14,15)$. However, the impact on EGFR-TKI-naive NSCLC patients has not been adequately investigated $(12,13,16)$. Recently, various therapies to overcome the T790M mutation are being developed. These include next generation EGFR-TKIs (18) and combination 

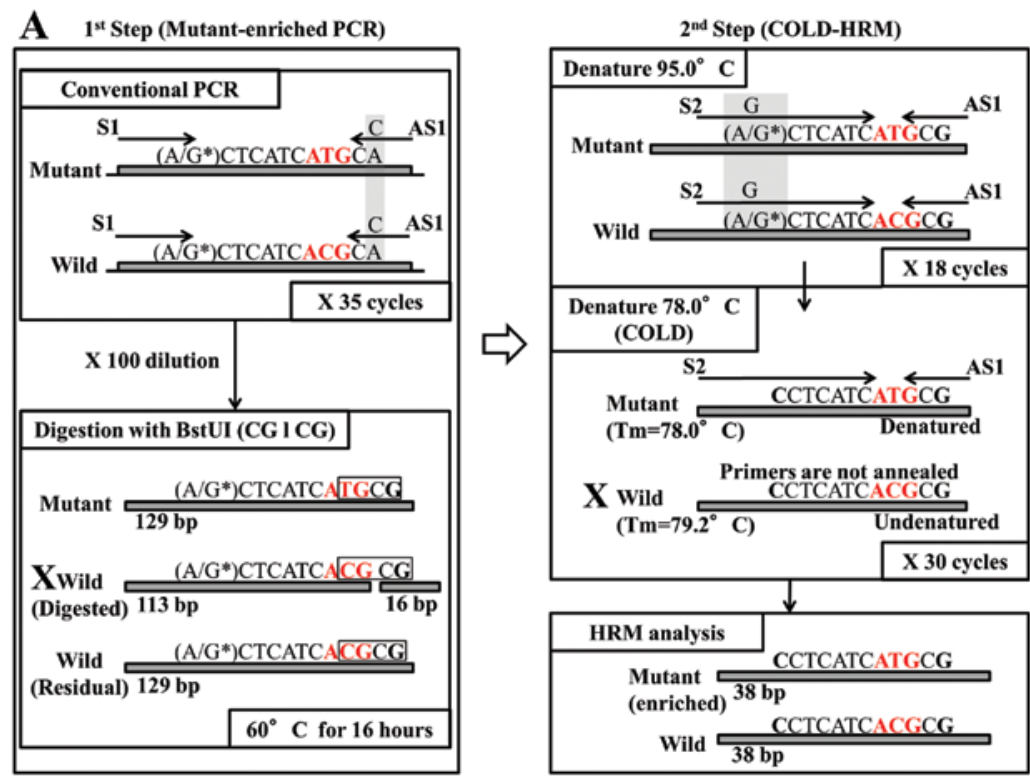

Figure 1. (A) Principle of the mutant-enriched COLD-HRM (MEC-HRM) assay. In the first step (left box), the upper box indicates the conventional PCR step for the amplification of EGFR exon 20, including codon 790. The mismatched site of the AS1 primer to introduce the CGCG sequence (framed) is emphasized with light gray shading. The exchanged bases are emphasized with bold print. An asterisk indicates the SNP site. The lower box indicates the step for the selective digestion of the wild-type amplicon. The crosses are applied on reduced amplicons. After digestion, the product that includes the mutant amplicon and residual undigested wild-type amplicon is used for the second step. The upper box indicates the first step of the real-time PCR for the amplification of the template product. The mismatched site of the S2 primer to diminish the influence of SNP is emphasized in light gray shading. The lower box indicates the second step, which is a COLD-PCR step for the selective amplification of the mutant. The $\mathrm{Td}\left(78.0^{\circ} \mathrm{C}\right)$ was lower than $\mathrm{Tm}$ of the wild-type amplicon; thus, they were not denatured and the primers were not annealed. The final products were analyzed using an HRM analysis.

therapies (19). Minor T790M mutated clones are enriched by EGFR-TKI treatment $(12,16)$; thus, early detection of a minor T790M mutation using a highly sensitive assay may be useful for predicting the cause of resistance to EGFR-TKIs and for selecting optimum therapeutic strategies.

In the present study, we determined the T790M mutational status using high-resolution melting (HRM) analysis combined with mutant-enriched $(12,20)$ and co-amplification at lower denaturation temperature (COLD)-polymerase chain reactions (PCRs) (21-24) to investigate the relationship between the presence of minor T790M mutations and clinicopathological factors in EGFR-TKI-naive lung adenocarcinoma patients with pulmonary resection.

\section{Materials and methods}

Clinical samples, cell lines and DNA extraction. We studied 146 patients with lung adenocarcinomas who underwent surgical resection without a preoperative history of EGFR-TKI treatment at our institute between 2006 and 2009. Approval of the Institutional Review Board and the informed consent of each patient were obtained. After pulmonary resection, fresh tissue was immediately frozen and stored at $-80^{\circ} \mathrm{C}$. DNA was extracted from the frozen tissue using proteinase $\mathrm{K}$ treatment followed by phenol-chloroform extraction (25). We also used a human bronchial epithelial cell line (HBEC-5KT) harboring the wild-type EGFR gene and the NCI-H1975 cell line (H1975) harboring the EGFR mutations L858R and T790M as negative and positive controls, respectively. These cell lines were kindly provided by Dr Adi F. Gazdar (The University of Texas Southwestern Medical Center at Dallas, Dallas, TX,
USA). DNA of the cell lines was extracted using the DNeasy Blood \& Tissue kit (Qiagen, Hilden, Germany).

Plasmids containing exon 20 of the EGFR gene. We used a plasmid containing EGFR exon 20 with the T790M mutation, which is one of the standardized plasmids containing each of the EGFR mutations occurring in the exons, and was used in a study by Goto et al (26). We also constructed a plasmid containing wild-type EGFR exon 20 using the TOPO TA Cloning Kit (Invitrogen, Carlsbad, CA, USA) as previously reported by us (27). The sequences of each plasmid were confirmed by direct sequencing.

Detection of EGFR exon 19 deletions and the L858R mutation. $E G F R$ exon 19 deletions and the exon 21 L858R mutation were examined using a restriction fragment length polymorphism (RFLP) assay without the enrichment of mutant alleles, as previously reported by us (20). We defined these EGFR exon 19 deletions and the exon 21 L858R mutation as drug-sensitive EGFR mutations.

Detection of the EGFR T790M mutation. Mutant-enriched COLD-HRM (MEC-HRM) is a two-step PCR-based assay combining a standard HRM assay with a mutant-enriched PCR $(12,20)$ that enriches the mutant allele by the intermittent restriction digestion of the wild-type allele and a COLD-PCR (21) that enriches the mutant allele by means of the difference in melting temperatures between the mutant and wild-type alleles. The principle of the MEC-HRM assay is shown in Fig. 1A.

As the first step, conventional PCR was performed to amplify the target region (129 base pairs), including codon 790 
B

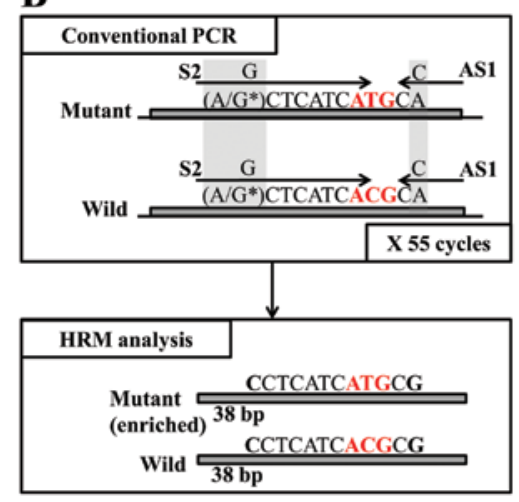

C

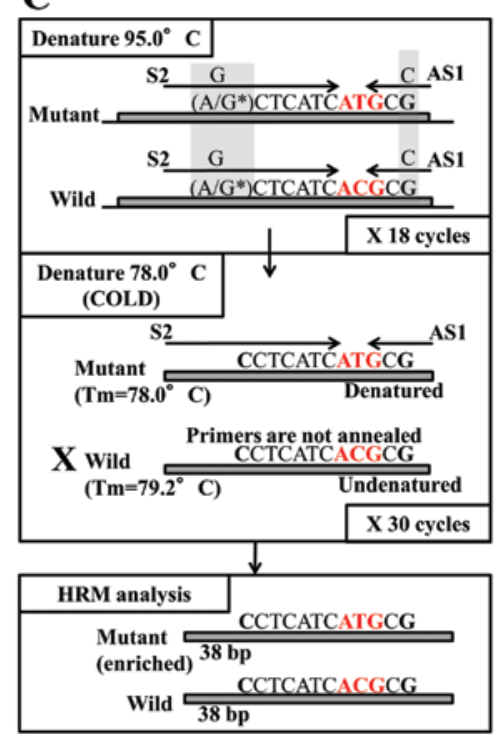

D $\quad 1^{\text {st }}$ Step (Mutant-enriched PCR)

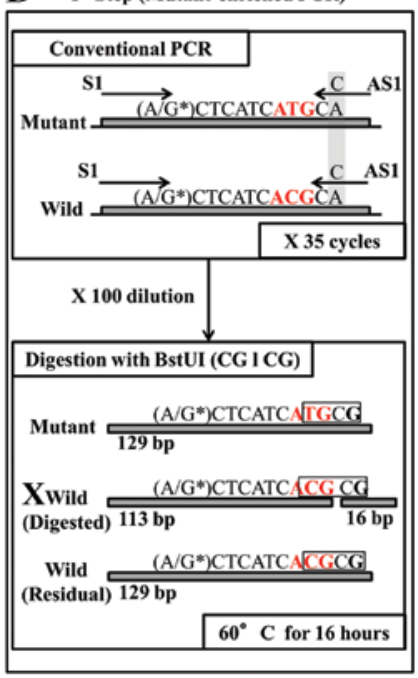

$2^{\text {md }}$ Step (COLD-HRM)

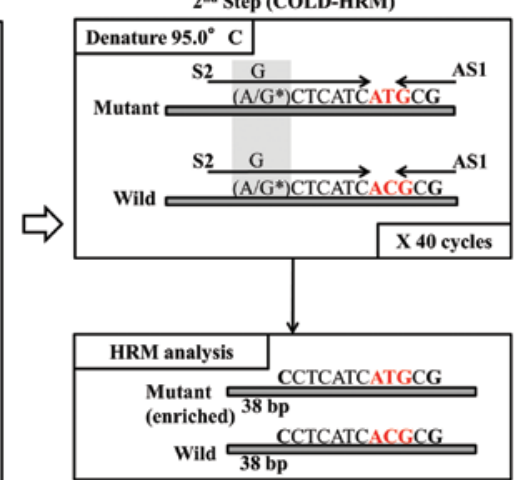

Figure 1. Continued. (B) Principle of standard HRM assay. The box indicates the real-time PCR step using the S2 primer (forward) and the AS1 primer (reverse). The real-time PCR conditions are as follows: an initial denaturation step at $95^{\circ} \mathrm{C}$ for $10 \mathrm{~min}$, and an amplification step for $55 \mathrm{cycles}\left(95^{\circ} \mathrm{C}\right.$ for $15 \mathrm{sec}$, $60^{\circ} \mathrm{C}$ for $60 \mathrm{sec}$ ). The final products are analyzed using HRM analysis. (C) Principle of COLD-HRM assay. The upper box indicates the first step of 18 cycles of real-time PCR for the amplification of the template product, and the lower box indicates the second step, which is a COLD-PCR step, for the selective amplification of the mutant allele. In the second step, the denaturing temperature (Td) is decreased to $78^{\circ} \mathrm{C}$ and amplification is performed for 30 cycles. The final products are analyzed using HRM analysis. (D) Principle of mutant-enriched HRM assay. In the first step (left box), conventional PCR and digestion are performed, similar to that shown in the left box of (A). The second step (right box) is performed in the same manner as standard HRM (B) using the products from the first step. Forty cycles are used for the mutant-enriched HRM assay, instead of 55 cycles for the standard HRM assay.

of the EGFR gene, using the GeneAmp ${ }^{\circledR} 9700$ thermal cycler (Applied Biosystems, Foster City, CA, USA). The forward primer sequence was 5'-ACTGACGTGCCTCTCCCTCC-3' (S1). The reverse primer sequence was 5'-CGAAGGGCATG AGCC*GC-3' (AS1), harboring one mismatched site (* T to C) to introduce the CGCG sequence into the amplicon of the wild-type. The final volume of the PCR mixture was $10 \mu \mathrm{l}$ contained $100 \mathrm{ng}$ of sample DNA, $150 \mathrm{nmol}$ of deoxynucleotide triphosphate, 2 pmol of each primer, and 1 unit of HotStarTaq DNA Polymerase Plus (Qiagen). The PCR conditions were as follows: an initial denaturation step at $95^{\circ} \mathrm{C}$ for $5 \mathrm{~min}$, followed by 35 cycles of $94^{\circ} \mathrm{C}$ for $20 \mathrm{sec}, 60^{\circ} \mathrm{C}$ for $30 \mathrm{sec}$, and $72^{\circ} \mathrm{C}$ for $20 \mathrm{sec}$. Diluted PCR products (100-fold dilution with distilled water) were treated with the restriction enzyme BstUI (New England BioLabs, Ipswich, MA, USA), which digests the wild-type allele but not the mutant allele, for $16 \mathrm{~h}$ at $60^{\circ} \mathrm{C}$, resulting in the enrichment of the mutant alleles, as previously reported by us (12).

After the first step, the second step (COLD-PCR, including melting curve analysis) was performed using the StepOnePlus ${ }^{\mathrm{TM}}$ real-time PCR system (Applied Biosystems). The forward primer sequence was 5'-CCTCCACCGTGCAC*CTCATC-3' (S2). Since one SNP site (rs1050171 A/G) exists in the S2 primer sequence, we designed a mismatched-base $(* \mathrm{C})$ at the SNP position to diminish the influence of the SNP (28). We used the AS1 primer as a reverse primer. The final volume of the PCR mixture was $20 \mu \mathrm{l}$, containing $10 \mu \mathrm{l}$ of MeltDoctor ${ }^{\mathrm{TM}}$ Master Mix (Applied Biosystems), 12 pmol of each primer and 
A

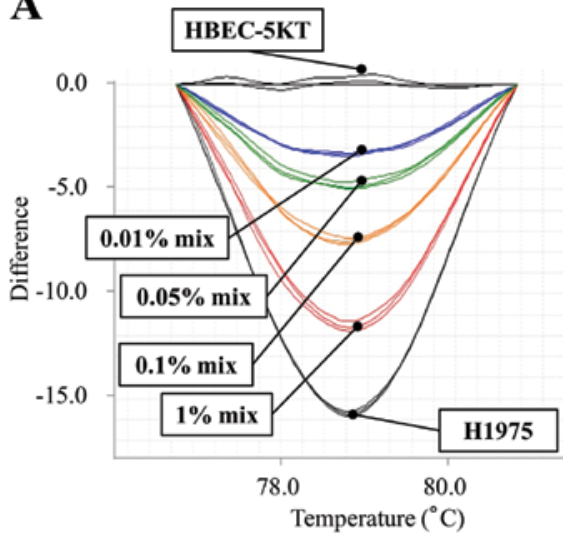

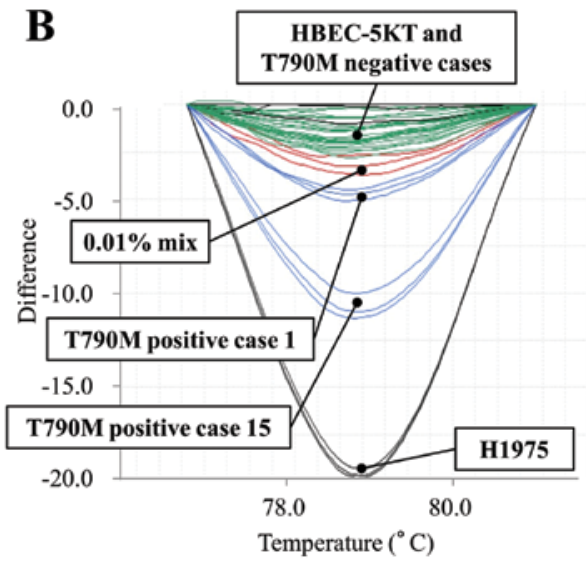

Figure 2. Sensitivity of MEC-HRM assay and representative clinical samples. (A) Difference plot showing the sensitivity of the MEC-HRM assay. We selected wild-type DNA (HBEC-5KT) for the standard of difference plots (horizontal line). Each percentage indicates the proportion of T790M-mutant DNA out of wild-type DNA. Consequently, the MEC-HRM assay was able to detect a T790M-mutant DNA (H1975) level of 0.01\% among wild-type DNA (HBEC-5KT). (B) The red curves indicate a DNA mixture containing $0.01 \%$ H1975 DNA among HBEC-5KT DNA. The green curves indicate the clinical samples determined as T790M-negative, and the blue curves indicate the samples determined as T790M-positive. Case 1 contains a $0.01-0.1 \%$ proportion of T790M clones, and case 15 contains a $0.1-1 \%$ proportion of T790M clones.

$1 \mu \mathrm{l}$ of the first-step product. The real-time PCR conditions were as follows: an initial denaturation step at $95^{\circ} \mathrm{C}$ for $10 \mathrm{~min}$, 18 cycles for the first round of standard amplification $\left(95^{\circ} \mathrm{C}\right.$ for $15 \mathrm{sec}, 60^{\circ} \mathrm{C}$ for $60 \mathrm{sec}$ ), and 30 cycles for the second round of amplification to enrich the mutant-amplicons $\left(78^{\circ} \mathrm{C}\right.$ for $15 \mathrm{sec}$ and $60^{\circ} \mathrm{C}$ for $60 \mathrm{sec}$ ). The denaturing temperature (Td) of the COLD-PCR step $\left(78^{\circ} \mathrm{C}\right)$ was determined using a melting curve analysis of the standard HRM [the melting temperatures (Tm) of the mutant-type and wild-type amplicons were $78^{\circ} \mathrm{C}$ and $79.2^{\circ} \mathrm{C}$, respectively] and an evaluation of the sensitivity of COLD-PCR from Td 79.2 to $78^{\circ} \mathrm{C}$ every $0.2^{\circ} \mathrm{C}$. After the amplification step, a melting curve was generated and analyzed using HRM software ver. 3.0.1 (Applied Biosystems).

We also performed standard-HRM, COLD-HRM and mutant-enriched HRM assays. The principles of these three assays are provided in Fig. 1B-D. All the samples, including the standard DNA mixtures, were analyzed in triplicate in all the assays. The sensitivities of all four assays were determined using multiple DNA mixtures of T790M mutant and wild-type alleles $(0.01,0.05,0.1,1,10,20$ or $50 \%$ of T790M mutant allele).

Statistical analysis. Chi-square tests or Fisher's exact tests were used to examine the differences in categorical factors across groups, as appropriate. The multivariate logistic regression model was used to identify clinicopathological factors that might independently predict the presence of T790M mutations.

After pulmonary resection, imaging studies were repeated every 3 months for at least 2 years and every 6 months thereafter for 3 years. After 5 years, medical examinations were repeated every year. The progression-free survival (PFS) was calculated from the date of surgery until confirmed disease recurrence or death. The overall survival (OS) was calculated from the date of surgery until the date of death or the last follow-up. The survival curve was calculated using the Kaplan-Meier method, and the difference between groups was compared using the log-rank test. Multivariate analyses were performed using the Cox proportional hazard model. All the data were analyzed using JMP, version 9.0.0 (SAS Institute Inc., Cary, NC, USA).
All the statistical tests were two-sided, and probability values (P) $<0.05$ were considered statistically significant.

\section{Results}

Sensitivity of each assay for the detection of the T790M mutation. The MEC-HRM assay was able to detect the T790M mutant allele in the sample with a mutant allele content of $0.01 \%$. In other words, it detected the mutant allele in the presence of a 10,000-fold background of wild-type allele (Figs. 2 and 3). Meanwhile, the detection limits of standard HRM, COLD-HRM and mutant-enriched HRM assays were a mutant allele content of 10,1 and $0.1 \%$, respectively (Fig. 4). Based on these data, we investigated the T790M mutation in 146 clinical samples using the standard HRM using a DNA mixture with T790M content of $10 \%$ as a positive control, and the MEC-HRM assays using a DNA mixture with T790M content of $0.01 \%$ as a positive control. Clinical samples and positive controls were investigated in the same plate in triplicate. When all three signals from a clinical sample exceeded the maximal signal from the control, the sample was identified to be positive for the T790M mutation (Fig. 2).

EGFR mutations in the clinical samples. Drug-sensitive EGFR mutations were found in 54 (37\%) of the 146 lung adenocarcinomas (26 exon 19 deletions and 28 L858R mutations). Drug-sensitive EGFR mutations were significantly associated with females $(\mathrm{P}<0.01)$ and never-smokers $(\mathrm{P}<0.01)$.

Although standard HRM did not detect any EGFR T790M mutations, EGFR T790M mutations were detected in 19 (13\%) of the 146 lung adenocarcinomas using the MEC-HRM assay. Thus, these 19 patients were defined as harboring minor T790M mutations. We confirmed that these 19 tumor samples had a tumor cell composition of at least $20 \%$ by examining the proportion of tumor cells in the tissue using hematoxylin and eosin staining. Next, we determined the dosage of the T790M mutant allele in 19 mutant samples by reanalyzing these samples and comparing them with $10,1,0.1$ and $0.01 \%$ standard T790M mutant DNA mixtures. We subcategorized the 


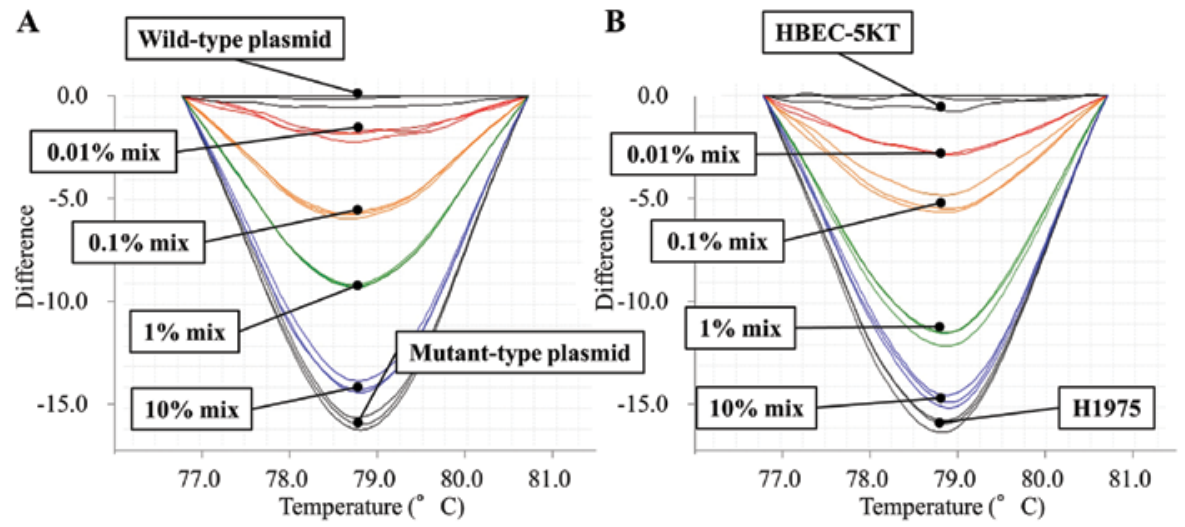

Figure 3. Comparison of sensitivities between plasmid and genomic DNA mixes. (A) The MEC-HRM assay was able to detect the T790M mutant allele at a level of $0.01 \%$ among wild-type alleles using the plasmid mixture. (B) The MEC-HRM assay showed similar sensitivities for the genomic DNA mixtures (H1975 and HBEC-5KT) and the plasmid mixtures.

A
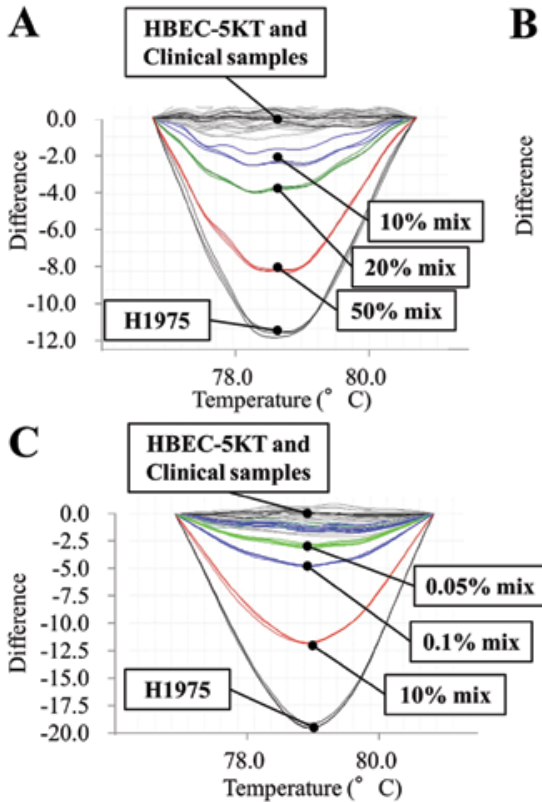

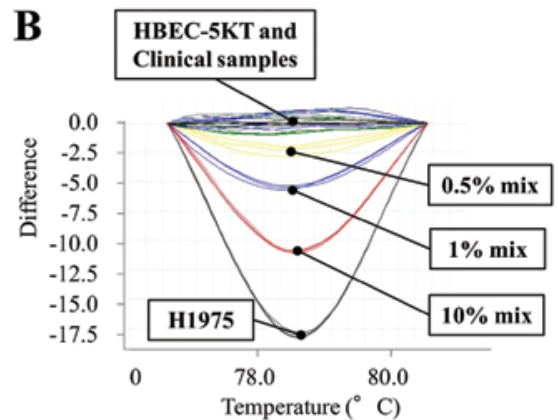

Figure 4. Sensitivities of standard HRM, COLD-HRM and mutant-enriched HRM assays. The difference plots for all three assays are shown. Wild-type DNA was used as a negative standard, and the percentages in each figure indicate the proportion of T790M-mutant DNA out of wild-type DNA. Consequently, the (A) standard HRM, (B) COLD-HRM and (C) mutant-enriched HRM assays were able to detect T790M-mutant DNA at levels of 10, 1 and 0.1\% among wild-type DNA, respectively.

19 minor T790M mutations into groups with T790M mutant DNA levels corresponding to $0.01-0.1 \%, 0.1-1 \%$ and $1-10 \%$. As shown in Table I, 17 of the 19 patients $(84 \%)$ had a T790M mutant allele proportion of $<0.1 \%$.

The details of the 19 patients harboring minor T790M mutations and the relationships between a minor T790M mutational status and clinicopathological factors are shown in Tables I and II, respectively. Minor T790M mutation was not significantly associated with age, gender, pathological stage, smoking history or drug-sensitive EGFR mutations in univariate analyses. However, drug-sensitive $E G F R$ mutations are considered to be associated with age, gender and smoking status $(27,29,30)$; thus, a multivariate analysis was performed to identify independent factors associated with a minor T790M mutation. Consequently, the minor T790M mutation was found to be independently associated with drug-sensitive $E G F R$ mutations (OR, 3.0; 95\% CI, 1.0-9.0; $\mathrm{P}=0.04$ ) (Table III).
Regarding the prognostic impact of the minor T790M mutation, it was not associated with either the OS or the PFS in our cohort (Table IV).

\section{Discussion}

In the present study, we determined the T790M mutational status using our newly developed, highly sensitive assay, the MEC-HRM assay. We previously developed a mutant-enriched PCR assay (sensitivity, 0.1\%) and found that the T790M mutation was detected in $3.8 \%$ of NSCLC patients without a history of treatment with EGFR-TKIs (12). Su et al (16) found that the T790M mutation was present in $25.2 \%$ of EGFR-TKInaive NSCLC patients using matrix-assisted laser desorption ionization-time of flight mass spectrometry (MALDI-TOF MS) (sensitivity, 1.5\%), and Oh et al (13) found that the T790M mutation was present in $8.2 \%$ of EGFR-TKI-naive NSCLC 
Table I. Details of the 19 T790M-positive patients.

\begin{tabular}{|c|c|c|c|c|c|c|}
\hline Case & $\begin{array}{c}\text { Age } \\
\text { (years) }\end{array}$ & Gender & Smoking history & $\begin{array}{l}\text { Pathological } \\
\text { stage }\end{array}$ & $\begin{array}{l}\text { Drug-sensitive } \\
E G F R \text { mutation }\end{array}$ & $\begin{array}{c}\text { Proportion of T790M } \\
\text { clones }\end{array}$ \\
\hline 1 & 59 & Male & Never-smoker & I & ex19 del. & $0.01-0.1 \%$ \\
\hline 2 & 75 & Male & Never-smoker & I & ex19 del. & $0.01-0.1 \%$ \\
\hline 3 & 75 & Female & Never-smoker & I & L858R & $0.01-0.1 \%$ \\
\hline 4 & 75 & Female & Never-smoker & I & L858R & $0.01-0.1 \%$ \\
\hline 5 & 79 & Female & Never-smoker & I & L858R & $0.01-0.1 \%$ \\
\hline 6 & 60 & Female & Never-smoker & I & WT & $0.01-0.1 \%$ \\
\hline 7 & 60 & Male & Never-smoker & III & WT & $0.01-0.1 \%$ \\
\hline 8 & 66 & Male & Smoker & $\mathrm{I}$ & ex19 del. & $0.01-0.1 \%$ \\
\hline 9 & 57 & Female & Smoker & I & ex19 del. & $0.1-1 \%$ \\
\hline 10 & 76 & Male & Smoker & I & ex19 del. & $0.01-0.1 \%$ \\
\hline 11 & 82 & Male & Smoker & I & L858R & $0.01-0.1 \%$ \\
\hline 12 & 58 & Male & Smoker & I & L858R & $0.01-0.1 \%$ \\
\hline 13 & 56 & Male & Smoker & I & WT & $0.01-0.1 \%$ \\
\hline 14 & 32 & Female & Smoker & I & WT & $0.1-1 \%$ \\
\hline 15 & 59 & Female & Smoker & I & WT & $0.01-0.1 \%$ \\
\hline 16 & 78 & Female & Smoker & I & WT & $0.01-0.1 \%$ \\
\hline 17 & 68 & Male & Smoker & I & WT & $0.01-0.1 \%$ \\
\hline 18 & 74 & Male & Smoker & I & WT & $0.01-0.1 \%$ \\
\hline 19 & 84 & Female & Smoker & II & L858R & $1-10 \%$ \\
\hline
\end{tabular}

ex19 del., exon 19 deletion; WT, wild-type. Drug-sensitive EGFR mutations include detection of exon19 deletions and the L858R mutation.

Table II. Relationship between minor T790M mutations and clinicopathological factors.

\begin{tabular}{|c|c|c|c|}
\hline Subsets $(n=146)$ & $\begin{array}{c}\text { T790M-positive }(\mathrm{n}=19) \\
\mathrm{n},(\%)\end{array}$ & $\begin{array}{c}\text { T790M-negative }(\mathrm{n}=127) \\
\mathrm{n},(\%)\end{array}$ & P-value \\
\hline \multicolumn{4}{|c|}{ Age (median; range) $(68 ; 32-87$ years $)$} \\
\hline$<68(\mathrm{n}=72)$ & $9(47.4)$ & $63(49.6)$ & 0.9 \\
\hline$\geq 68(n=74)$ & $10(52.6)$ & $64(50.4)$ & \\
\hline \multicolumn{4}{|l|}{ Gender (male vs. female) } \\
\hline Male $(n=71)$ & $10(52.6)$ & $61(48.0)$ & 0.7 \\
\hline Female $(n=75)$ & $9(47.4)$ & $66(52.0)$ & \\
\hline \multicolumn{4}{|l|}{ Smoking history } \\
\hline Smoker $(n=74)$ & $12(63.2)$ & $62(48.8)$ & 0.2 \\
\hline Never-smoker $(n=72)$ & $7(36.8)$ & $65(51.2)$ & \\
\hline \multicolumn{4}{|l|}{ Pathological stage } \\
\hline I $(n=103)$ & $17(89.5)$ & $86(67.7)$ & 0.06 \\
\hline II $(n=12)$ & $1(5.3)$ & $11(8.7)$ & (I vs. others) \\
\hline III $(n=21)$ & $1(5.3)$ & $20(15.7)$ & \\
\hline $\operatorname{IV}^{\mathrm{a}}(\mathrm{n}=10)$ & $0(0.0)$ & $10(7.9)$ & \\
\hline \multicolumn{4}{|c|}{ Drug-sensitive $E G F R$ mutation } \\
\hline Mutant $(\mathrm{n}=54)$ & $10(52.6)$ & $44(34.6)$ & 0.1 \\
\hline Wild $(n=92)$ & $9(47.4)$ & $83(65.4)$ & \\
\hline
\end{tabular}

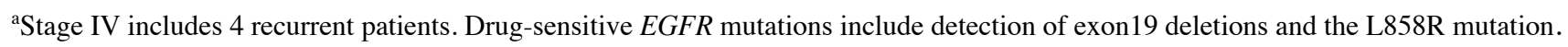


Table III. Multivariate analysis of the minor T790M mutationrelated factors.

\begin{tabular}{llc}
\hline Variables & OR (95\% CI) & P-value \\
\hline $\begin{array}{l}\text { Age (years) } \\
\quad(<68 \text { vs. } \geq 68)\end{array}$ & $1.0(0.4-2.6)$ & 1.0 \\
$\begin{array}{l}\text { Gender } \\
\quad \text { Male vs. female) }\end{array}$ & $0.6(0.2-2.5)$ & 0.5 \\
$\begin{array}{l}\text { Smoking history } \\
\text { (Smoker vs. never-smoker) }\end{array}$ & $3.8(0.9-18)$ & 0.08 \\
$\begin{array}{l}\text { Drug-sensitive EGFR mutation } \\
\text { (Mutant vs. wild) }\end{array}$ & $3.0(1.0-9.0)$ & 0.04 \\
\hline
\end{tabular}

OR, odds ratio; CI, confidence interval. Drug-sensitive EGFR mutation include detection of exon19 deletions and the L858R mutation.

patients using peptide nucleic acid (PNA)-clamping PCR with a melting curve analysis (sensitivity, $0.01 \%$ ). The present study revealed that the MEC-HRM assay could detect the T790M mutation in $13 \%$ of EGFR-TKI-naive adenocarcinomas. Of note, our standard HRM assay (10\% sensitivity) did not detect any T790M-positive specimens, and we considered all the T790M mutations that were detected using the MEC-HRM assay to be minor mutations $(2,17)$.

As novel findings, the minor T790M mutation was significantly associated with drug-sensitive EGFR mutations in a multivariate analysis. Previous reports have described that drug-sensitive EGFR mutations and the T790M mutation generally occur in cis (31-33), although the statistical relationship between minor T790M mutation and drug-sensitive EGFR mutations has never been revealed in clinical samples. Our present study is, to the best of our knowledge, the first report to confirm that the minor T790M mutation was significantly associated with drug-sensitive EGFR mutations in lung adeno- carcinomas. To understand this situation, two issues should be discussed: i) the relationship between drug-sensitive EGFR mutations and the T790M mutation, and ii) the presence of the T790M mutation as a minor population. Regarding the first issue, while the reason for this association is unknown, lung cancers with germ-line EGFR mutations such as T790M (31), V843I (34), and R776H (35) are accompanied by additional EGFR mutations in the development of lung cancer, suggesting that $E G F R$ mutations themselves cause genetic instability, thereby predisposing cells to additional mutations within the gene (34). The second issue can be explained by the following hypothesis. During the carcinogenic process of EGFR-mutantrelated lung cancer, drug-sensitive $E G F R$ mutations occur first in the progenitor cells of lung cancer, followed by the T790M mutation. At this stage, the tumor consists of a heterogeneous population of drug-sensitive EGFR mutant cells with or without the T790M mutation. Previous studies have reported that drug-sensitive EGFR mutant cells with an additional T790M mutation exhibit an indolent progression, indicating that the possession of the T790M mutation is a disadvantage for cell proliferation (36). This fact suggests that cancer cells with only drug-sensitive EGFR mutations may be dominant in tumors, in addition to those with T790M and drug-sensitive EGFR mutations as a minor population.

Our study also suggested that the T790M mutation tended to be associated with a smoking history in this study. Drug-sensitive EGFR mutations are known to be frequent in never-smokers with NSCLCs. However, drug-sensitive EGFR mutations themselves have not been reported to be associated with a never-smoking habit (30). Matsuo et al (30) indicated that EGFR mutations presumably occur in both smokers and never-smokers with a similar incidence, but other smoking-related mutations such as TP53 or KRAS mutations preferentially occur in smokers resulting in the enrichment of the prevalence of EGFR mutations in never-smokers. In fact, the average mutation frequency has been reported to be $>10$-fold higher in smokers than in never-smokers (37). Considering these observations, the EGFR mutation at codon

Table IV. Multivariate analysis for recurrence and mortality.

\begin{tabular}{|c|c|c|c|c|}
\hline \multirow[b]{2}{*}{ Variables } & \multicolumn{2}{|c|}{ PFS } & \multicolumn{2}{|c|}{ OS } \\
\hline & $\mathrm{HR}(95 \% \mathrm{CI})$ & P-value & $\mathrm{HR}(95 \% \mathrm{CI})$ & P-value \\
\hline Age (<68 vs. $\geq 68$ years $)$ & $0.3(0.1-0.6)$ & $<0.01$ & $0.3(0.1-0.9)$ & 0.02 \\
\hline Gender (Male vs. female) & $0.7(0.2-1.9)$ & 0.4 & $1.0(0.3-3.6)$ & 0.9 \\
\hline $\begin{array}{l}\text { Smoking history } \\
\text { (Smoker vs. never-smoker) }\end{array}$ & $2.3(0.8-7.3)$ & 0.1 & $2.1(0.6-8.5)$ & 0.3 \\
\hline Pathological stage (I vs. II-IV) & $0.2(0.09-0.4)$ & $<0.01$ & $0.2(0.05-0.4)$ & $<0.01$ \\
\hline $\begin{array}{l}\text { Drug-sensitive } E G F R \text { mutation } \\
\text { (Mutant vs. wild) }\end{array}$ & $1.0(0.4-2.2)$ & 1.0 & $0.5(0.1-1.4)$ & 0.2 \\
\hline $\begin{array}{l}\text { T790M mutation } \\
\text { (Mutant vs. wild) }\end{array}$ & $0.5(0.08-1.8)$ & 0.3 & $1.7(0.4-5.9)$ & 0.4 \\
\hline
\end{tabular}

PFS, progression-free survival; OS, overall survival; HR, hazard ratio; CI, confidence interval. Drug-sensitive EGFR mutations include detection of exon19 deletions and the L858R mutation. 
790, unlike drug-sensitive EGFR mutations, might be susceptible to tobacco-related carcinogens.

In conclusion, we revealed an association between the minor T790M mutation and clinicopathological factors in surgically resected lung adenocarcinoma patients without a history of EGFR-TKI treatment using our novel, highly sensitive assay. Minor T790M mutations are independently associated with drug-sensitive EGFR mutations.

\section{Acknowledgements}

The authors thank Ms. Fumiko Isobe (Department of Thoracic, Breast and Endocrinological Surgery, Okayama University Graduate School of Medicine, Dentistry and Pharmaceutical Sciences, Okayama, Japan) for her technical support. The present study was supported by a Grant-in Aid for Scientific Research from the Ministry of Education, Culture, Sports, Science and Technology of Japan (S.T.).

\section{References}

1. Mitsudomi T, Morita S, Yatabe Y, et al: Gefitinib versus cisplatin plus docetaxel in patients with non-small-cell lung cancer harbouring mutations of the epidermal growth factor receptor (WJTOG3405): an open label, randomised phase 3 trial. Lancet Oncol 11: 121-128, 2010.

2. Sequist LV, Martins RG, Spigel D, et al: First-line gefitinib in patients with advanced non-small-cell lung cancer harboring somatic EGFR mutations. J Clin Oncol 26: 2442-2449, 2008.

3. Lynch TJ, Bell DW, Sordella R, et al: Activating mutations in the epidermal growth factor receptor underlying responsiveness of non-small-cell lung cancer to gefitinib. N Engl J Med 350: 2129-2139, 2004.

4. Yamamoto $\mathrm{H}$, Toyooka $\mathrm{S}$ and Mitsudomi T: Impact of EGFR mutation analysis in non-small cell lung cancer. Lung Cancer 63 315-321, 2009.

5. Kosaka T, Yatabe Y, Endoh H, Kuwano H, Takahashi T and Mitsudomi T: Mutations of the epidermal growth factor receptor gene in lung cancer: biological and clinical implications. Cancer Res 64: 8919-8923, 2004.

6. Araki T, Yashima H, Shimizu K, et al: Review of the treatment of non-small cell lung cancer with gefitinib. Clin Med Insights Oncol 6: 407-421, 2012.

7. Kobayashi S, Boggon TJ, Dayaram T, et al: EGFR mutation and resistance of non-small-cell lung cancer to gefitinib. N Engl J Med 352: 786-792, 2005

8. Sequist LV, Waltman BA, Dias-Santagata D, et al: Genotypic and histological evolution of lung cancers acquiring resistance to EGFR inhibitors. Sci Transl Med 3: 75ra26, 2011.

9. Oxnard GR, Arcila ME, Sima CS, et al: Acquired resistance to EGFR tyrosine kinase inhibitors in EGFR-mutant lung cancer: distinct natural history of patients with tumors harboring the T790M mutation. Clin Cancer Res 17: 1616-1622, 2011.

10. Eck MJ and Yun CH: Structural and mechanistic underpinnings of the differential drug sensitivity of EGFR mutations in non-small cell lung cancer. Biochim Biophys Acta 1804: 559-566, 2010.

11. Maheswaran S, Sequist LV, Nagrath S, et al: Detection of mutations in EGFR in circulating lung-cancer cells. N Engl J Med 359: 366-377, 2008

12. Inukai M, Toyooka S, Ito S, et al: Presence of epidermal growth factor receptor gene $\mathrm{T} 790 \mathrm{M}$ mutation as a minor clone in non-small cell lung cancer. Cancer Res 66: 7854-7858, 2006.

13. Oh JE, An CH, Yoo NJ and Lee SH: Detection of low-level EGFR T790M mutation in lung cancer tissues. APMIS 119: 403-411, 2011.

14. Fujita Y, Suda K, Kimura H, et al: Highly sensitive detection of EGFR T790M mutation using colony hybridization predicts favorable prognosis of patients with lung cancer harboring activating EGFR mutation. J Thorac Oncol 7: 1640-1644, 2012.
15. Rosell R, Molina MA, Costa C, et al: Pretreatment EGFR T790M mutation and BRCA1 mRNA expression in erlotinibtreated advanced non-small-cell lung cancer patients with EGFR mutations. Clin Cancer Res 17: 1160-1168, 2011.

16. Su KY, Chen HY, Li KC, et al: Pretreatment epidermal growth factor receptor $(E G F R)$ T790M mutation predicts shorter EGFR tyrosine kinase inhibitor response duration in patients with nonsmall-cell lung cancer. J Clin Oncol 30: 433-440, 2012.

17. Toyooka S, Kiura $\mathrm{K}$ and Mitsudomi $\mathrm{T}$ : EGFR mutation and response of lung cancer to gefitinib. N Engl J Med 352: 2136, 2005.

18. Sakuma Y, Yamazaki Y, Nakamura Y, et al: WZ4002, a thirdgeneration $E G F R$ inhibitor, can overcome anoikis resistance in $E G F R$-mutant lung adenocarcinomas more efficiently than $\mathrm{Src}$ inhibitors. Lab Invest 92: 371-383, 2012.

19. Regales L, Gong Y, Shen R, et al: Dual targeting of EGFR can overcome a major drug resistance mutation in mouse models of EGFR mutant lung cancer. J Clin Invest 119: 3000-3010, 2009.

20. Asano H, Toyooka S, Tokumo M, et al: Detection of EGFR gene mutation in lung cancer by mutant-enriched polymerase chain reaction assay. Clin Cancer Res 12: 43-48, 2006.

21. Li J, Wang L, Mamon H, Kulke MH, Berbeco $\mathrm{R}$ and Makrigiorgos GM: Replacing PCR with COLD-PCR enriches variant DNA sequences and redefines the sensitivity of genetic testing. Nat Med 14: 579-584, 2008.

22. Luthra R and Zuo Z: COLD-PCR finds hot application in mutation analysis. Clin Chem 55: 2077-2078, 2009.

23. Milbury CA, Li J and Makrigiorgos GM: COLD-PCR-enhanced high-resolution melting enables rapid and selective identification of low-level unknown mutations. Clin Chem 55: 2130-2143, 2009.

24. Song C, Milbury CA, Li J, Liu P, Zhao M and Makrigiorgos GM: Rapid and sensitive detection of KRAS mutation after fastCOLD-PCR enrichment and high-resolution melting analysis. Diagn. Mol Pathol 20: 81-89, 2011.

25. Fan $\mathrm{H}$ and Gulley ML: DNA extraction from fresh or frozen tissues. Methods Mol Med 49: 5-10, 2001.

26. Goto K, Satouchi M, Ishii G, et al: An evaluation study of EGFR mutation tests utilized for non-small-cell lung cancer in the diagnostic setting. Ann Oncol 23: 2914-2919, 2012.

27. Tokumo M, Toyooka S, Kiura K, et al: The relationship between epidermal growth factor receptor mutations and clinicopathologic features in non-small cell lung cancers. Clin Cancer Res 11: 1167-1173, 2005

28. Do H, Krypuy M, Mitchell PL, Fox SB and Dobrovic A: High resolution melting analysis for rapid and sensitive $E G F R$ and $K R A S$ mutation detection in formalin fixed paraffin embedded biopsies. BMC Cancer 8: 142, 2008.

29. Ueno T, Toyooka S, Suda K, et al: Impact of age on epidermal growth factor receptor mutation in lung cancer. Lung Cancer 78: 207-211, 2012.

30. Matsuo K, Ito H, Yatabe Y, et al: Risk factors differ for non-smallcell lung cancers with and without EGFR mutation: assessment of smoking and sex by a case-control study in Japanese. Cancer Sci 98: 96-101, 2007

31. Bell DW, Gore I, Okimoto RA, et al: Inherited susceptibility to lung cancer may be associated with the T790M drug resistance mutation in EGFR. Nat Genet 37: 1315-1316, 2005.

32. Soh J, Okumura N, Lockwood WW, et al: Oncogene mutations, copy number gains and mutant allele specific imbalance (MASI) frequently occur together in tumor cells. PLoS One 4: e7464, 2009.

33. Pao W, Miller VA, Politi KA, et al: Acquired resistance of lung adenocarcinomas to gefitinib or erlotinib is associated with a second mutation in the EGFR kinase domain. PLoS Med 2: e73, 2005.

34. Ohtsuka K, Ohnishi H, Kurai D, et al: Familial lung adenocarcinoma caused by the EGFR V843I germ-line mutation. J Clin Oncol 29: e191-e192, 2011.

35. van Noesel J, van der Ven WH, van Os TA, et al: Activating germline $\mathrm{R} 776 \mathrm{H}$ mutation in the epidermal growth factor receptor associated with lung cancer with squamous differentiation. J Clin Oncol 31: e161-e164, 2013.

36. Chmielecki J, Foo J, Oxnard GR, et al: Optimization of dosing for EGFR-mutant non-small cell lung cancer with evolutionary cancer modeling. Sci Transl Med 3: 90ra59, 2011.

37. Govindan R, Ding L, Griffith M, et al: Genomic landscape of non-small cell lung cancer in smokers and never-smokers. Cell 150: $1121-1134,2012$ 